Oehrberg, S., Christiansen, P. E., Behnke, K., et al (1995) Paroxetine in the treatment of panic disorder, a randomised, double-blind placebo-controlled study. British Journal of Psy chiatry, 167, 374-379.

Power, K. G., Smpson, R. J., Swanson, V., et al (1990) A controlled comparison of cognitive behaviour therapy, diazepam and placebo, alone and in combination for the treatment of generalised anxiety disorder. Journal of Anxiety Disorders, 4, 267-292.

Sharp, D. M., Power, K. G., Simpson, R. J., et al Fluvoxamine placebo and cognitive behaviour therapy, used alone and in combination in the treatment of panic disorder and agoraphobia. Journal of Anxiety Disorders, in press.

D. M. SHARP

K. G. POWER

Anxiety and Stress Research Centre

R. J. SIMPSON

University of Stirling

Stirling FK9 4LA

\section{Homicidal behaviour and mental disorders}

SIR: The important study of Modestin \& Ammann (1995) includes some misleading conclusions. The writers emphasise that "women with mental disorders ... were no more likely than controls to have committed violent crimes". Their data shows that the female psychiatric in-patients committed six violent crimes whereas the controls committed none. Although the statistical test used by the authors did not indicate statistical significance, this may be a type 1 error. The authors also conclude that schizophrenia and affective disorders do not elevate the risk of violent behaviour, but alcoholism does. However, among men, the odds ratios for violent crimes was 3.1 for schizophrenia and 8.8 for affective disorders. The fact that $99 \%$ confidence intervals were very wide (lower ends below 0.6 ) was due to the small number of subjects, and therefore, the authors' conclusion on major mental disorders and the risk of violent behaviour is dubious. The authors' conclusion that "mental disorders ... do not contribute to criminal behaviour" cannot be verified in a statistically significant way (with $99 \%$ CI) to be true or false in their relatively small sample.

We have analysed all forensic psychiatric examinations conducted on persons charged with a homicide during several years in Finland. Our results indicate that schizophrenia is associated with up to a 10-fold risk of committing a homicide among women (OR 10.8; 95\% CI 5.5-21.3) and with about a 7-fold risk among men (OR 6.7; 95\% CI 2.7-16.3). The odds ratio for alcoholism was about 16 (OR 16.0; 95\% CI 11.3-22.6) among men and about 50 (OR 48.8; 95\% CI 33.571.2) among women, when compared with the general population (Tiihonen et al, 1993; Eronen, 1995). The lower ends of $95 \%$ CI were clearly above 1.0 which indicates that the risk increase is significant at the $95 \%$ level. In a recent Finnish 3year sample of homicide recidivists all offenders were type 2 alcoholics $(85 \%)$ or schizophrenics (15\%) (Tiihonen \& Hakola, 1994) which also indicates that schizophrenia and the combination of alcoholism and personality disorders are the most important mental disorders causing homicidal behaviour.

ERONEN, M. (1995) Mental disorders and homicidal behavior in female subjects. American Journal of Psychiatry, 152, 12161218

Modestin, J. \& AmmanN, R. (1995) Mental disorders and criminal behavior. British Journal of Psychiatry, 166, 667-675.

Tilhonen, J., Eronen, M. \& Hakola, P. (1993) Criminality associated with mental disorders and intellectual deficiency. Archives of General Psychiatry, 50, 917-918.

- \& Hakola, P. (1994) Psychiatric disorders and homicide recidivism. American Journal of Psychiatry, 151, 436-438.

J. TIIHONEN

P. HAKOLA

M. ERONEN

University of Kuopio

Niuvanniemi Hospital

FIN-70240 Kuopio

Finland

\section{Seizure threshold in bilateral and unilateral ECT}

SIR: Abrams et al (1973) reported shorter seizure durations with unilateral compared with bilateral ECT, and this has been confirmed by Weiner (1980). The general consensus of opinion is that bilateral ECT is associated with longer seizures compared with unilateral treatment. In addition, as seizure threshold increases, the seizure duration decreases and vice versa. However, the recent College video on ECT states that bilateral ECT is associated with an increased seizure threshold compared with unilateral treatment, and this is reiterated in the accompanying handbook. We would welcome clarification on this by the Special Committee on ECT as we are involved with the teaching of ECT to junior psychiatrists and regularly use both the video and handbook as a teaching aid.

Abrams, R., Volavka, J. \& Fink, M. (1973) EEG seizure patterns during multiple unilateral and bilateral ECT. Comprehensive Psychiatry, 14, 25-28. 